\title{
Drinking water desalination using low-cost Tubular Solar Still
}

\author{
Azrina Karima $^{1} \cdot$ Kh. Md. Shafiul Islam ${ }^{1}$
}

Received: 26 July 2017 / Accepted: 30 October 2019 / Published online: 11 November 2019

(c) The Author(s) 2019

\begin{abstract}
Growing freshwater scarcity in arid and remote areas usually is caused by the growth of population, urbanization and industrialization and the rather limited natural resources of potable water. In coastal belt of southwest region of Bangladesh, groundwater contains high salinity as well as excessive arsenic contamination. Though pond sand filter and rainwater harvesting system are usually used to meet the freshwater demand throughout the year in this area, along with these, household-based solar desalination could be a good source of drinking water in this region. In this study, a low-cost Tubular Solar Still (TSS) was designed using locally available materials to meet such demand. It was consisted of a tubular frame $(0.00275 \mathrm{~m}$ thick helical GI wire, $1.0 \mathrm{~m}$ long and $0.2 \mathrm{~m}$ in diameter) and a rectangular tray $(1.0 \mathrm{~m} \times 0.16 \mathrm{~m} \times 0.05 \mathrm{~m})$ covered with black polythene paper. The collection bottle was kept in an insulation box. The field experiment on the constructed TSS was carried out on the rooftop of Civil Engineering Department building from June 25, 2011, to June 20, 2012. Daily distilled output from the TSS was collected approximately $2 \mathrm{~h}$ after sunset. The maximum daily production rate was found as $3.831 / \mathrm{m}^{2}$ in May 2012. The production cost of distilled water is estimated as $0.39 \mathrm{BDT} / \mathrm{L}$ or $0.0046 \mathrm{USD} / \mathrm{L}$. The application of this process can fulfill the demand of freshwater for drinking purpose for single household in coastal areas.
\end{abstract}

Keywords Freshwater $\cdot$ Natural resources $\cdot$ Production rate $\cdot$ Renewable energy $\cdot$ Solar desalination

\section{Introduction}

The origin and continuation of mankind are based on water. Water is one of the most abundant resources on earth, covering three-fourth of the planet's surface. However, about ninety-seven percent of the earth's water is salt water in the oceans and a tiny three percent is freshwater. In this three percent of freshwater, not hundred percent is drinkable (Ahsan and Fukuhara 2010). Clean drinking water is a basic human need. Many people, especially in developing countries, do not have access to clean drinking water. On the other hand, water from underground cannot be a permanent solution as it is limited and decrement of groundwater can be turned harmful to nature and existing infrastructures (Varun 2010). Also water from surface water sources may be contaminated in various ways. Salinity problem is a great problem in coastal areas in Bangladesh. As an effect of global warming, the sea level is rising and the salinity

Azrina Karima

azrina.karima@yahoo.com

1 Department of Civil Engineering, Khulna University of Engineering and Technology, Khulna 9203, Bangladesh problem is affecting areas beyond coast. The potable drinking water and irrigation water are thus becoming scarce day by day (Deng et al. 2011). The energy source is also an important aspect. For water purification or distillation, an external energy source is needed. But continuous usage of the conventional energy sources is the main cause of reduction in these sources gradually. If some renewable energy sources of water desalination can be introduced, a reduction in conventional energy usage can be confirmed. A reduction of just 5 percent in global energy use may save the equivalent of more than 10 million barrels of oil per day. The solar energy is one of the renewable energies can be used without any difficulties (Akbarzadeh et al. 2011).

Solar desalination already has taken valuable place in brackish or seawater desalination process. Various water desalination processes have been being operated with the help of solar power (Li et al. 2013). The current solar desalination systems still have relatively high capital cost, low proficiency and productivity and dependency on location, weather and season which make it uncompetitive with the conventional ones. However, solar desalination is a feasible choice for the arid region with small water demands for developing countries due to the elimination of the high cost 
of the water transportation and costly energy source. For developing counties like Bangladesh, the most practical renewable desalination technique could be solar distillation which is a simply natural evaporation-condensation process with a low-cost energy source (Alkaisi et al. 2016).

Solar distillation practice is not new in Bangladesh. A lot of researches have been going on for a development of improved solar still with a better yield of saline-free drinking water (Islam et al. 2013). Due to deep water pumps, the people living along coastal areas do not suffer much from water scarcity, but the water contains high salinity which is next to impossible to drink. In these areas, people solely depend on rainwater harvesting for drinking water. Often, they suffer from lack of drinking water which leads to various diseases (Scheelbeek et al. 2017). For these reasons, water desalination techniques for household use have been studied a lot.

Among the extensive studies with rectangular and basintype solar stills, the latter one is a better choice for the rapid removal of the salt accumulation at the bottom of the basin and ease in its repair (Ahsan et al. 2010).

In this paper, different low-cost Tubular Solar Stills (TSSs) using locally available and non-native exported materials were developed. Field experiments were carried out on the rooftop of the Civil Engineering Department of Khulna University of Engineering and Technology from June 25, 2011, to June 20, 2012. The study mainly aimed at developing low-cost TSSs using different materials, monitoring and comparing their performance by collecting data from the TSSs.

\section{Development of TSS and field experiment}

\section{Production principle of TSS}

After transmission through a tubular cover, the solar radiation is mainly absorbed by saline water in the trough. The tubular cover and trough absorb the remaining small amount of the solar energy. Thus, the water in the trough is heated and then begins to evaporate. The type of heat transfer occur inside and outside the tubular cover are- evaporative heat transfer from the saline water to the tubular cover, condensing heat transfer between the saline water and the tubular cover, the trough and the water, trough and the tubular cover and the cover and the atmosphere, and radioactive heat transfer between the water surface and the tubular cover and the tubular cover and the atmosphere. The evaporative water vapor is transferred to the tubular cover and then finally condensed on the tubular cover inner surface, releasing its latent heat of vaporization. The condensed water drops down at the bottom of the inner surface of tubular cover due to gravity and is stored in the collection bottle through a pipe provided at the middle of the still. Figure 1 shows the diagram of production principle of the TSS.

\section{Construction and field experiment}

A low-cost Tubular Solar Still (TSS) was developed with locally available products to minimize the cost most effectively, and another one was developed with Japanese polyethylene sheet to compare their difference in production rate of saline-free water. Both consisted of tubular frames made of $0.00275 \mathrm{~m}$ thick helical GI wire. The pitch of the spiral ring was about $0.05 \mathrm{~m}$. The frame was $1.0 \mathrm{~m}$ long and $0.2 \mathrm{~m}$ in diameter which was covered with a durable (expected design life is 4 years), transparent polythene sheet (one was local and the other was Japanese). A rectangular trough $(1.0 \mathrm{~m} \times 0.16 \mathrm{~m} \times 0.05 \mathrm{~m})$ made of carton paper, was covered with black polythene paper to store the brackish water. The distilled water was collected in a plastic bottle kept inside a wooden box for insulation purpose. The constructed TSS was set on a wooden frame to give support to it. The experiment was done with brackish drinking water which had high saline content. For this reason, no additional experiment was done for determining the water quality parameters.

The field experiment was carried out on the rooftop of Civil Engineering Department of Khulna University of Engineering and Technology, from June 25, 2011, to June 20, 2012. One end of the TSS was closed permanently, and the other end was closed temporarily to give brackish water as input. The daily output of distilled water from the TSS is collected approximately $2 \mathrm{~h}$ after sunset. Figure 2 shows the photograph of the field experiment.

\section{Results and discussion}

The distilled output from the TSS was collected everyday approximately $2 \mathrm{~h}$ after sunset from June 25, 2011 to June 20, 2012. After collecting the daily distilled output from the TSS, the reading was recorded. With these recorded data,

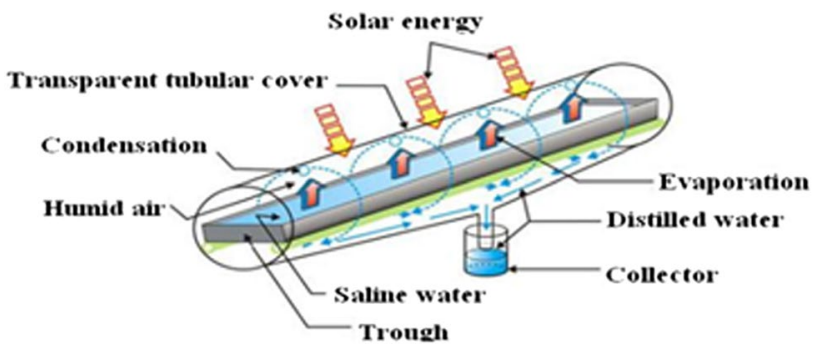

Fig. 1 Production principle of the TSS 


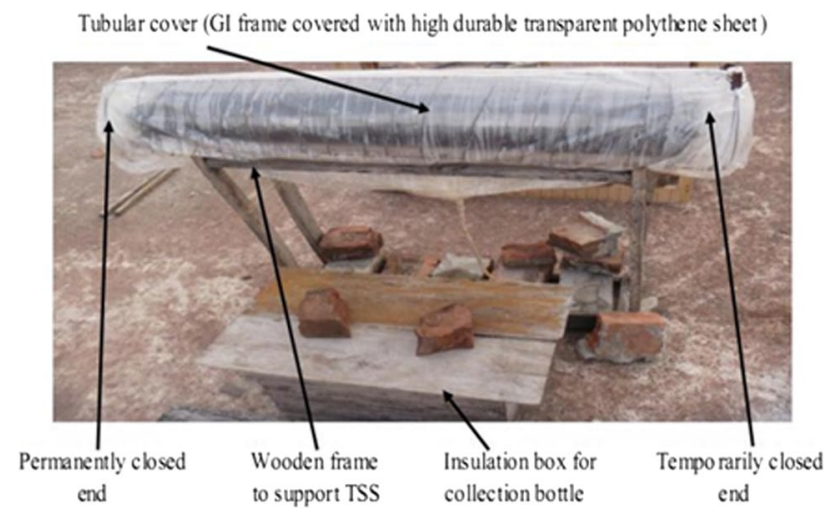

Fig. 2 Photograph of the field experiment

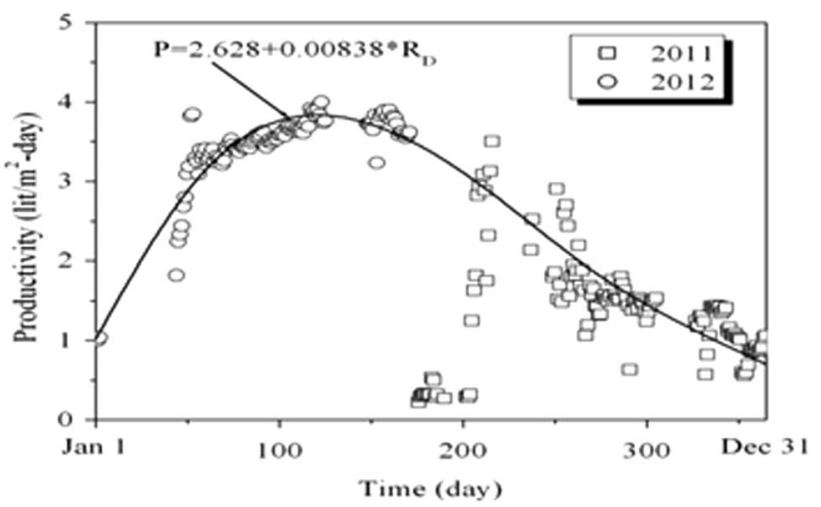

Fig. 3 Daily distilled output from the TSS

the following graphical representation was done. Figure 3 shows the daily production of distilled water from the TSS.

The above figure shows that the maximum water output is obtained in the month of May. The output is highest in the summer season (March-June); then, gradually it decreases in the rainy season (July-October), and then, again it starts increasing in winter season (November-February). The typical average temperature and rainfall data of the seasons in Bangladesh are depicted in Fig. 4. The figure indicates that, though the precipitation starts from early to mid-June, the average temperature needs some time to reduce. For this, even when the rainfall is high, due to higher average temperature the distilled output does not reduce at first. The continuation of the increased rainfall minimizes the average monthly temperature and so does the distilled output. As the day time is maximum and the sunlight is extreme in summer season, naturally the output is highest. The average production rate is then calculated from the daily distilled output for every month's data and also, the peak production rate is found out and listed in Table 1.

The average and peak production rate of the TSS is represented in Fig. 5 from which the difference in average and
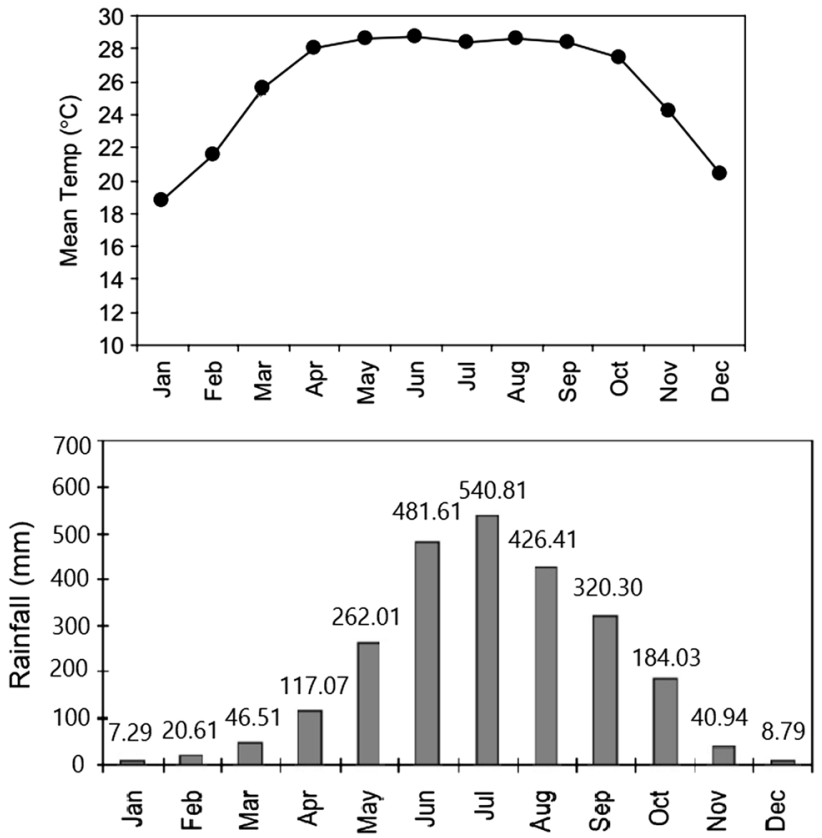

Fig. 4 Typical average monthly temperature and rainfall data in Bangladesh

Table 1 Summary of daily production rate of the TSS

\begin{tabular}{lll}
\hline Month (2011-2012) & $\begin{array}{l}\text { Average production } \\
\text { rate }\left(1 / \mathrm{m}^{2} / \text { day }\right)\end{array}$ & $\begin{array}{l}\text { Peak production } \\
\text { rate }\left(1 / \mathrm{m}^{2} / \text { day }\right)\end{array}$ \\
\hline July & 1.01 & 2.03 \\
August & 0.63 & 1.12 \\
September & 0.88 & 1.56 \\
October & 1.33 & 1.53 \\
November & 0.96 & 1.43 \\
December & 1.55 & 1.84 \\
January & 1.97 & 1.97 \\
February & 2.35 & 2.50 \\
March & 2.59 & 2.68 \\
April & 2.73 & 3.34 \\
May & 3.09 & 3.83 \\
June & 2.80 & 3.38 \\
\hline
\end{tabular}

peak distilled outputs for different months can be easily understood.

The difference in average and peak production rate for different months is clearly depicted in Fig. 5. The pattern of water output shows clearly the monthly and seasonal variation of production of distilled water. The maximum production rate in May and minimum production rate in August are found as 3.83 and $1.12 \mathrm{~L} / \mathrm{m}^{2} /$ day, respectively, in case of peak production and 3.09 and $0.63 \mathrm{~L} / \mathrm{m}^{2} /$ day, respectively, in case of average production. The average production rate 
Fig. 5 Comparison between average and peak production rate for the TSS for different months

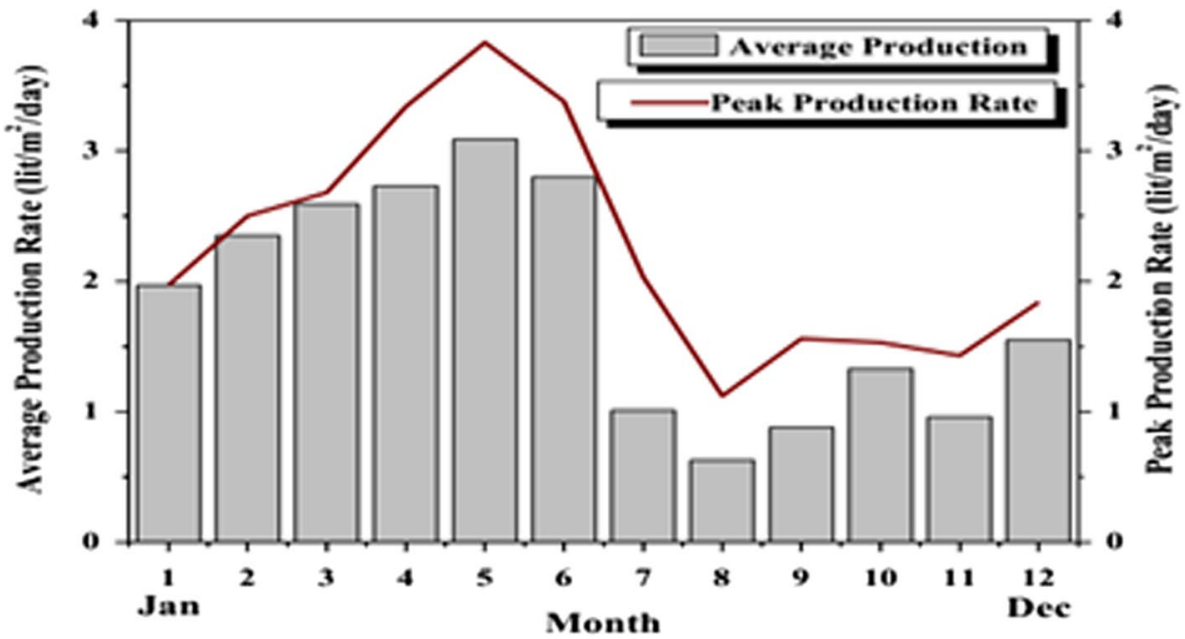

Table 2 Cost analysis for the TSS (according to 2018)

\begin{tabular}{llllll}
\hline S. no. & Item description & Unit & Rate (BDT) & Quantity & $\begin{array}{c}\text { Amount } \\
\text { in BDT }\end{array}$ \\
\hline 1 & GI wire & $\mathrm{m}$ & 30 & 3 & 110 \\
2 & Trough & - & 70 & - & 70 \\
3 & Polythene & $\mathrm{m}$ & 35 & 1 & 35 \\
4 & Miscellaneous & - & - & - & 30 \\
Total & & & & & 245 \\
\hline
\end{tabular}

throughout the study period is found as $1.93 \mathrm{~L} / \mathrm{m}^{2} /$ day $(0.31$ L/day).

Cost analysis for the TSS is carried out by summing up different cost measurements of its constituents and by measuring unit production cost and represented in Table 2 after reevaluation based on 2018 pricing. The construction cost of each TSS is found as BDT 245, and the production cost of the distilled water is estimated as $0.77 \mathrm{BDT} / \mathrm{L}$. For a person, if he/she consumes $2 \mathrm{~L}$ distilled water per day, in that case, the number of TSS required $=2 / 0.31=6.4 \approx 7$ nos.

Design life of the TSS $=4$ years

Construction cost of the TSS $=245$ BDT

Operation and maintenance cost throughout design life (one-time change of trough and polythene) $=105 \mathrm{BDT}$

Total distilled water production in the design life $=4 \times 365 \times 0.31=452.61$

Production cost of water $=(245+105) / 452.6=0.77$ BDT/1

Field experiments were carried out on different solar stills for a comparative discussion from June 2011 to June 2012, named as Tubular Solar Still with normal polythene cover (TSS 1) and Tubular Solar Still with Japanese polythene cover (TSS 2). Finally, comparison in different
Table 3 Comparison of different types of solar still

\begin{tabular}{lllll}
\hline $\begin{array}{l}\text { Type of solar } \\
\text { still }\end{array}$ & $\begin{array}{l}\text { Initial } \\
\text { cost } \\
\text { (BDT) }\end{array}$ & $\begin{array}{l}\text { Design } \\
\text { life } \\
\text { (year) }\end{array}$ & $\begin{array}{l}\text { Average daily } \\
\text { production (l/ } \\
\text { m }^{2} \text {-day) }\end{array}$ & $\begin{array}{l}\text { Production } \\
\text { cost of distilled } \\
\text { water (BDT/l) }\end{array}$ \\
\hline TSS 1 & 245 & 4 & 1.93 & 0.77 \\
TSS 2 & 380 & 5 & 2.64 & 0.70 \\
\hline
\end{tabular}

aspects between these solar stills was made and is represented in Table 3. The variation of initial cost, design life, daily productivity and production cost of distilled water for different solar stills is shown in Fig. 6.

From Fig. 6, a comparison between two TSSs is made to show their performances more clearly. The TSS 2 (made of Japanese polythene, which is only available in few markets) has greater initial cost, a better design life and a better water output than the TSS 1 . The production cost of distilled water of TSS 1 is $0.77 \mathrm{BDT} / \mathrm{L}$ which is slightly greater than the production cost of TSS $2(0.70$ BDT/L). Though the production cost of TSS 1 is slightly high, the constituent materials are available everywhere, even in arid rural areas. The production cost of TSS 2 would increase if the TSS was not properly maintained. Considering all aspects, TSS 1 is a better choice for household usage.

Previous studies have shown that the depth of the brine should be kept under $0.04 \mathrm{~m}$ which was maintained in this experiment for maximum yield. The yield would reduce if the salinity increased. So, the yield of projected TSS might have reduced if the experiment had been done with seawater. The amount of the output has fluctuated due to climatic condition, wind speed and the intensity of the solar radiation. Use of surfactant additives and nanoparticles in varying water depth along with condenser and external reflector can certainly improve the function of the TSS which also 
Fig. 6 Variation of design life, initial cost, average daily productivity and production cost for different TSSs

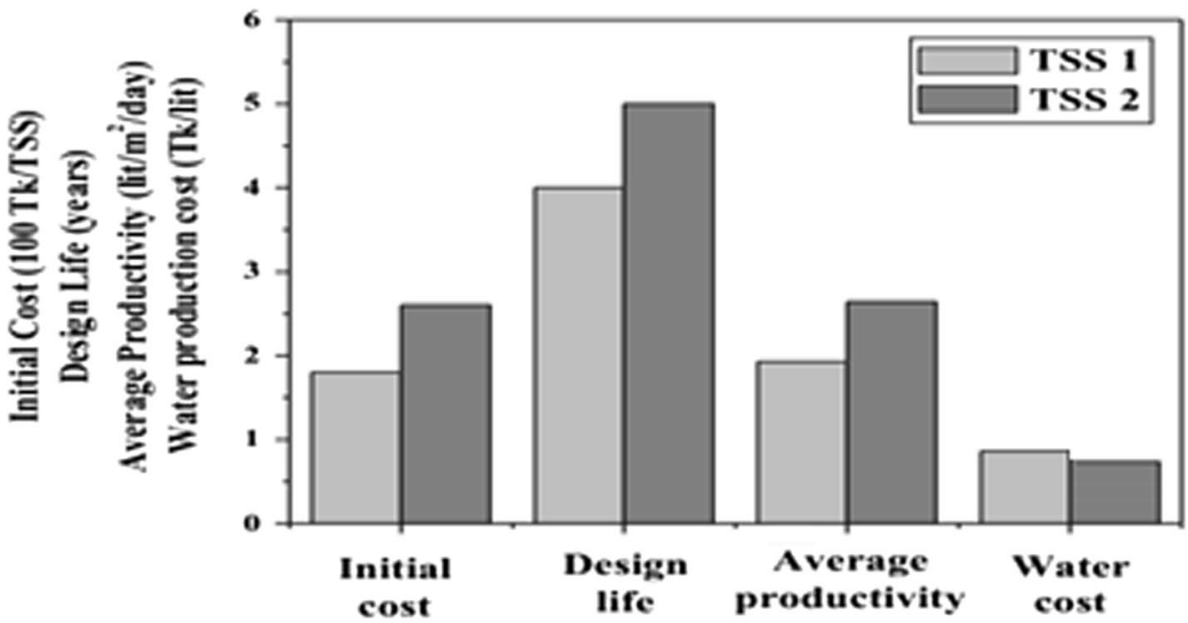

increases the cost of water production and makes the model complicated.

The limitation of this experiment is that it has got no water quality parameter test result included. As subsurface saline water was used for this experiment, no water quality parameters had been checked for further verification. In case of advance research project for large-scale application, water quality parameter test should be included to check whether this experiment is useful in microbial and pathogenic removal as well as degree of salinity control. Also, the efficiency of this experimental setup has yet to be determined as the output water has still got some salinity. Any minute fracture in polythene sheet can yield low efficiency in this experiment.

Solar distillation can be a very useful and cost-effective means of providing clean water for drinking, cooking, washing and bathing — four basic human needs. Where seawater is available, it can reduce a developing country's dependence on rainfall. But, for commercial use, the TSS should be modified as the 'trough made of carton paper' cannot hold huge amount of water. Though the output of solar still depends on the climatic, thermal, still design or other related technical factors, it is one of the best solutions for pure drinking water in arid and coastal regions for its easy maintenance and environment-friendly characteristics.

\section{Conclusion}

The TSS is developed for domestic purposes in rural household and community of the coastal belt of Bangladesh. For this reason, the construction method was kept simple, userfriendly and cost economic.

It is obvious that the performance of the TSSs under different climatic conditions fluctuates, respectively. The production rate of desalinated water is maximum in the summer and minimum in the rainy season.
The factors which affect the distilled water production can be controlled to some extent, and the output may be increased. As no inherent technical or economic barrier has been identified, a solar still can provide water supply more economically than any other method. The application of this process can fulfill the demand of saline-free potable water for single household in coastal and arid regions.

In case of commercial packaging of this TSS, some modification including use of internal or external reflectors, use of good insulation system or wick evaporation surface could enhance the water production rate which also could bring solution to drinking water scarcity in coastal region of developing countries.

\section{Compliance with ethical standards}

Conflict of interest The authors declare that there is no conflict of interest in this study.

Open Access This article is distributed under the terms of the Creative Commons Attribution 4.0 International License (http://creativeco mmons.org/licenses/by/4.0/), which permits unrestricted use, distribution, and reproduction in any medium, provided you give appropriate credit to the original author(s) and the source, provide a link to the Creative Commons license, and indicate if changes were made.

\section{References}

Ahsan A, Fukuhara T (2010) Mass and heat transfer model of Tubular Solar Still. Sol Energy 84:1147-1156

Ahsan A, Islam KMS, Fukuhara T, Ghazali AH (2010) Experimental study on evaporation, condensation and production of a new Tubular Solar Still. Desalination 260:172-179

Akbarzadeh A, Peska T, Singh R, Wassouf P (2011) Novel and low cost designs of portable solar stills. Desalination 276:294-302

Alkaisi A, Mossad R, Sharifian-Barforoush A (2016) A review of the water desalination systems integrated with renewable energy. Energy Procedia 110:268-274

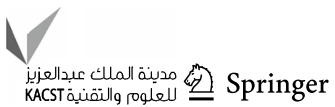


Deng S, Gude VG, Nirmalakhandan N (2011) Desalination using solar energy: towards sustainability. Energy 36:78-85

Islam MM, Uddin SA, Islam Z, Hossain MI (2013) An experimental study on small scale sea water desalination unit through solar power in Cox's Bazar, Bangladesh. J Bangladesh Agric Univ 11(1):165-170

Li C, Goswami Y, Stefanakos E (2013) Solar assisted sea water desalination: a review. Renew Sustain Energy Rev 19:136-163

Scheelbeek PFD, Chowdhury MAH, Haines A, Alam DS, Hoque MA, Butler AP, Khan AE, Mojumder SK, Blangiardo MAG, Elliott P, Vineis $P$ (2017) Drinking water salinity and raised blood pressure: evidence from a cohort study in coastal Bangladesh. Environ Health Perspect 125(5):057007

Varun AK (2010) Solar stills: a review. Renew Sustain Energy Rev $14: 446-453$

Publisher's Note Springer Nature remains neutral with regard to jurisdictional claims in published maps and institutional affiliations. 